\title{
Reducing the Global Burden of Depression
}

Prabjyot Kaur CHAHIL* 1

1 Student, University of Ottawa, Canada

*Auteur(e) correspondant | Corresponding author : Pchah050@uottawa.ca

\section{Résumé :}

(traduction)

\section{Mots-clés :}

\section{Abstract:}

Keywords:
On s'attend à ce que la dépression deviennent l'une des principales causes de morbidité d'ici 2020. Toutefois, les méthodes actuelles de traitement pour la dépression risquent de ne pas être efficaces dans la réduction du fardeau mondial que pourrait devenir cette maladie. Actuellement, la pharmacothérapie représente la première ligne de traitement pour les troubles dépressifs, néanmoins de nombreux effets indésirables liés aux antidépresseurs sont souvent négligés et leur interférence avec la chimie du corps peut ne pas être idéal pour un traitement à long terme.

Afin de réduire le fardeau de cette maladie, d'autres méthodes de traitement tels que le coaching et les thérapies doivent être considérées comme des solutions de rechange à la pharmacothérapie. Plus important encore, ces traitements réduisent l'apparition d'une rechute vers la dépression, ce qui les rend plus efficaces à long terme. En plus des méthodes alternatives de traitement, les stratégies de prévention de la dépression devrait être une priorité. Non seulement la prévention de la dépression est la meilleure solution thérapeutique, mais elle est aussi la plus rentable pour réduire la morbidité mondiale. La mise en œuvre de telles stratégies requiert cependant plus de données factuelles sur la prévention des troubles dépressifs.

Traitement de la dépression, antidépresseurs, Thérapie cognitive comportementale, counseling, prévention de la dépression

Depression is expected to be one of the leading causes of morbidity by 2020 . Nonetheless, the current methods of treatment for depression may not be effective in reducing the global burden of this disease. Currently, pharmacotherapy represents the first line treatment for depressive disorders; however, many adverse effects of anti-depressants are often overlooked and their interference with body chemistry may not be ideal for long-term treatment.

In order to reduce the burden of disease of depression, methods of treatment such as counseling and therapy should be considered as alternatives to pharmacotherapy. Most importantly, these treatments reduce the occurrence of depression relapse, making them more effective in the long-term. In addition to alternative methods of treatment, depression prevention strategies should be prioritized. Not only is depression prevention the best solution therapeutically, but it is also the most cost-effective in reducing global morbidity. In order to implement these strategies, however, more evidence-based research on the prevention of depressive disorders is required.

Depression treatment, antidepressants, cognitive behavioral therapy, counseling, depression prevention 
By the year 2020, depression is estimated to be the second leading cause of disability adjusted life years (DALYs) calculated for all ages (Reddy, 2010). The term DALY refers to one year of life lost due to death or disability (World Health Organization, 2014) and is used as a measure of morbidity within a population. Current attitudes towards treatment of depression will not reduce its present and projected disease burden. Conversely, improving measures to treat and prevent chronic depression may help to reduce the incidence of DALYs. First, the disadvantages of the current method of treatment should be recognized. Second, alternative and effective methods of treatment should be provided. Finally, it is important that gaps in knowledge of depression prevention be filled in order to reduce the rising number of DALYs.

The current method of treating depression is through pharmacotherapy; however, the adverse effects of medication are often disregarded. Antidepressants often create a sense of dependency, meaning the illness is kept in remission rather than being truly cured. Andrews and colleagues (2012) support this notion by describing how antidepressants increase the brain's susceptibility to future depressive episodes after they have been discontinued. In addition, certain anti-depressants may interfere with body chemistry and produce adverse effects in patients. For example, gastrointestinal problems, central nervous system problems, hypernatremia and bleeding are known side effects of specifically selective serotonin reuptake inhibitors (SSRIs), the first-line treatment for depression (Khawam, Laurencic, \& Malone, 2006). Khawam and colleagues (2006) also identified side-effects as the most common reason for premature anti-depressant discontinuation, which is evident in $44 \%$ of patients after three months of treatment. As such, from the patient's perspective the harm caused by anti-depressants is not worth the treatment benefits they provide.

The role of pharmaceutical company's agendas in the debate against antidepressants is also an important factor in causing public skepticism about drug effectiveness. In a systemic literature review, Turner and colleagues (2008) found that drug companies selectively publish studies on antidepressants and omit those reporting the drugs as ineffective. This suggests that the business and revenue goals of these pharmaceutical companies may trump their interest in providing an effective treatment. In addition, for many depression patients the emotion-numbing effect of antidepressants may actually enhance the self-destructive behaviours that the drugs are meant to prevent. For example, Padala and colleagues (2012) suggest that certain antidepressants, specifically SSRIs, contribute to feelings of lost motivation and apathy in patients with depression. Consequently, the use of pharmacotherapy may exacerbate depressive symptoms rather than treat them. For both of these reasons, alternative methods of treatment should be recognized.

Instead of only targeting the biomedicine of depression, alternative treatments include more holistic approaches such as counseling and therapy. These non-invasive methods take into account the patient's personal experiences and environment, which may have acted as triggers for the depression. There is substantial evidence suggesting that counseling and cognitive therapy are equally effective alternatives to antidepressants in treating depression. DeRubeis, Siegle, and Hollon (2008) performed a metaanalysis and found no differences in the outcomes of cognitive therapy versus pharmacotherapy in severely depressed patients. Chilvers (2001) also discovered similar results for generic counseling, stating that it is an equally effective treatment for mild to moderate depressive illness. Vittengl, Clark, Dunn, and Jarrett (2007) found that there were lower rates of depression recurrence after cognitive behavioural therapy in comparison to pharmacotherapy. In addition to an equivalent efficacy in treating immediate symptoms, counseling and therapy reduce the likelihood of relapse in depression patients, as they target the initial causes of depression. Therefore, unlike pharmacotherapy, counseling methods attempt to find a permanent and longterm solution for the treatment of depressive disorders.

In addition to improving the alleviation of depression and preventing its relapse among individual patients, the implementation of prevention strategies may reduce the burden of disease expected from depression on a population level. Cuijpers, Beekman, and Reynolds (2012) have demonstrated that preventative measures such as psychotherapeutic and lifestyle interventions reduce the incidence of depression by $25-30 \%$. In financial analysis, Cuijpers and colleagues (2012) have also found that the cost of averting 1 DALY due to depression is below the current ceiling of $\$ 30,000$ to $\$ 50,000$, generally accepted by policy makers as cost-effective. Depression prevention may thus be the most effective strategy to decrease DALYs as it encompasses both economics and therapeutic benefits for patients; however, in order to effectively establish effective depression prevention strategies, more evidence-based research is required. Until such time, simple preventative measures for depression are available, such as controlling 
stress levels, boosting self-esteem, and seeking friendship and social support (Mayo Clinic, 2014).

In order to effectively reduce the DALYs caused by depression, it is necessary that the disadvantages associated with antidepressants are acknowledged within the scientific community, cognitive behavioral therapy and counseling is more frequently selected as a treatment method, and evidence-based research on prevention is established. The use of antidepressants alone to treat depression will likely result in remission and eventual relapse of depressive episodes, while counseling, therapy and prevention will collectively benefit the population in the long term.

\section{References}

Andrews, P. W., Thomson, J. A., Jr., Amstadter, A., \& Neale, M. C. (2012). Primum non nocere: An evolutionary analysis of whether antidepressants do more harm than good. Frontiers in Psychology, 3, 117. doi: 10.3389/

fpsyg.2012.00117

Chilvers, C., Dewey, M., Fielding, K., Gretton, V., Miller, P., Palmer, B., ... \& Harrison, G. (2001). Antidepressant drugs and generic counselling for treatment of major depression in primary care: Randomised trial with patient preference arms. British Medical Journal, 322(7289), 772-776. doi: 10.1136/bmj.322.7289.772

Cuijpers, P., Beekman, A. T., \& Reynolds, C. F., III. (2012). Preventing depression: A global priority. Journal of the American Medical Association, 307(10), 1033-1034. doi: 10.1001/jama.2012.271

DeRubeis, R. J., Siegle, G. J., \& Hollon, S. D. (2008). Cognitive therapy vs. medications for depression: Treatment outcomes and neural mechanisms. Nature Reviews Neuroscience., 9(10), 788-796. doi: 10.1038/nrn2345

Khawam, E. A., Laurencic, G., \& Malone, D. A., Jr. (2006). Side effects of antidepressants: An overview. Cleveland Clinic Journal of Medicine, 73(4), 351-353, 356-361.

Mayo Clinic. (2014). Depression (major depressive disorder). Retrieved May 9, 2014, from http:// www.mayoclinic.org/diseases-conditions/depression/ basics/prevention/con-20032977
Padala, P. R., Padala, K. P., Monga, V., Ramirez, D. A., \& Sullivan, D. H. (2012). Reversal of SSRI-associated apathy syndrome by discontinuation of therapy. Annals of Pharmacotherapy, 46(3), e8. doi: 10.1345/aph.1Q656

Reddy, M. (2010). Depression: The disorder and the burden. Indian Journal of Psychological Medicine, 32(1), 12. doi: 10.4103/0253-7176.70510

Turner, E. H., Matthews, A. M., Linardatos, E., Tell, R. A., \& Rosenthal, R. (2008). Selective publication of antidepressant trials and its influence on apparent efficacy. New England Journal of Medicine, 358(3), 252-260. doi: 10.1056/NEJMsao65779

Vittengl, J. R., Clark, L. A., Dunn, T. W., \& Jarrett, R. B. (2007). Reducing relapse and recurrence in unipolar depression: A comparative meta-analysis of cognitivebehavioral therapy's effects. Journal of Consulting and Clinical Psychology, 75(3), 475-488.

World Health Organization. (2014). Metrics: Disabilityadjusted life year (DALY). Retrieved from http:// www.who.int/healthinfo/global_burden_disease/ metrics_daly/en/ 